\title{
Dia-log: análise de marcadores verbais para identificação de déficits de comunicação em autismo
}

\author{
Roberto dos Santos Rabello $^{1}$, Liliana Maria Passerino ${ }^{2}$, Rosa Vicari $^{3}$ \\ PPGIE- Universidade Federal do Rio Grande do Sul (UFRGS) \\ Av. Paulo Gama, 110 - Prédio 12105 - Porto Alegre - RS - Brazil \\ roberto.rabello@ufrgs.br, liliana@cinted.ufrgs.br, rosa@inf.ufrgs.br
}

Resumo. Este artigo descreve como um software que utiliza agentes inteligentes pode auxiliar na identificação de marcadores conversacionais em ambientes de comunicação síncrona aplicados a pessoas autistas. Com base na detecção destes marcadores, e conseqüentemente dos déficits de conversação, podem ser propostos mecanismos de compensação que auxiliem na comunicação destes sujeitos.

Palavras Chave: autista, marcadores, agentes inteligentes

\begin{abstract}
This article describes how a software that uses intelligent agents can assist in identifying markers in conversational environments of synchronous communication applied to autistic people. Based on the detection of these markers, and consequently the deficits of conversation, may be offered compensation mechanisms that help in communicating these subjects.
\end{abstract}

Key words: autistic, markers, intelligent agents

\section{Introdução}

A conversação é um dos elementos da comunicação aonde os interlocutores podem interagir e efetuar trocas de conhecimentos que acabarão normalmente no resultado cognitivo. No caso do autismo a limitação de comunicação se caracteriza na dificuldade de utilizar, com sentido, todos os aspectos da comunicação verbal e não verbal. Incluindo gestos, expressões faciais, linguagem corporal, ritmo e modulação da linguagem verbal, da ecolalia. Além disso, a dificuldade de sociabilização é um elemento crucial no autismo e o mais fácil de gerar falsas interpretações. Significa a dificuldade em relacionar-se com os outros, compartilhar sentimentos, gostos e emoções. Essas dificuldades de comunicação e interação social acabam gerando problemas sociais e de isolamento de pessoas com autismo, principalmente enquanto adolescentes ou adultos, pois, normalmente, deixam de freqüentar o espaço escolar. Nestes casos, ficam isolados, dependentes de familiares e amigos para que os levem a passeios ou a ambientes que proporcionem uma vida social dita "normal" e, muitas vezes, acabam permanecendo em casa, assistindo programas de TV ou acessando a internet. No caso da internet, mais especificamente os comunicadores síncronos, podese ter uma interação maior através do uso da tecnologia. Na comunicação, seja ela 
verbal ou não verbal, os marcadores são importantes para garantir uma fluência, lógica e compreensão do processo conversacional. Estes marcadores são palavras ou expressões bastante estereotipadas. Eles aparecem no contexto geral, particular ou pessoal da conversação, e não dependem especialmente de novas informações para o desenvolvimento do tópico. Existem marcadores de dois tipos: os de interação e os de processamento. Os marcadores conversacionais de interação são produzidos pelo falante e pelo ouvinte, e são sempre "conjunto de partículas, palavras, sintagmas, expressões estereotipadas e orações ou ainda expressões lexicalizadas". É o caso de "então", "né”, "veja bem", "você não acha?", "sim", "claro", "com certeza", "ah sim", “e aí?", "duvido!", “mesmo!", "hum”, entre diversos outros elementos.

Já os marcadores conversacionais de processamento são produzidos apenas pelo falante, e refletem uma organização do pensamento - entre eles situam-se as disfluências que, inicialmente, seriam falhas ocorridas durante o processamento da linguagem. Visto que as disfluências desempenham um papel importante na linguagem falada, faz-se necessário um estudo de seus tipos, suas causas, seus efeitos na compreensão das sentenças, enfim, de todos os seus aspectos.

Diante da importância da comunicação para a interação social e da interação social para o desenvolvimento das pessoas, especialmente dos sujeitos autistas, busca-se com esse trabalho propor um software que auxilie na análise dos marcadores verbais para posteriormente propor mecanismos de compensação para os déficits de comunicação identificados.

\section{Comunicação e CMC}

Os processos comunicativos entre os seres humanos tiveram início por uma necessidade de cooperação entre os homens. Eles precisavam encontrar uma forma de unir-se em busca de objetivos comuns para que a sobrevivência da espécie fosse possível. A comunicação possibilitou e efetivou a criação dos elos que os semelhantes necessitavam. De acordo com Watzlawick, Beavin e Jackson (2000), se todo o comportamento, numa situação interacional, tem valor de mensagem, isto é, é comunicação, indica que, por mais que o indivíduo se esforce, é impossível não comunicar. Ainda, de acordo com estes autores, até a própria inatividade ou silêncio possuem valor de mensagem, influenciam outros e estes, por sua vez, não podem não responder a essas comunicações e, portanto, também estão comunicando.

Também não pode-se dizer que a comunicação só acontece quanto existem intencionalidade, ou quando é consciente ou bem sucedida, isto é, quando ocorre uma compreensão mútua.

[...] se a mensagem enviada iguala a mensagem recebida é importante, mas diferente ordem de análise, pois que deve assentar, fundamentalmente, nas avaliações de dados específico, introspectivos, relatados pelo sujeito, os quais preferimos negligenciar para a exposição de uma teoria comportamental de comunicação (WATZLAWICK; BEAVIN; JACKSON, 2000).

Para que haja troca comunicativa, não basta que dois ou mais indivíduos falem de forma alternada, é preciso que todos os participantes estejam envolvidos na troca e engajados 
com o processo, recorrendo aos diversos procedimentos de validação interlocutória. Os cumprimentos, apresentações, saudações e outros rituais desempenham um papel importante, mas a validação interlocutória se consolida por meios importantes como (kebrat -ORECCHINI, 1996) o emissor, o receptor e a sincronização interacional que corresponde principalmente pelo funcionamento dos turnos de fala, comportamentos corporais dos participantes da interação, escolhas dos temas, registro de troca, etc.

A comunicação é central para a interação social e esta pode interferir significativamente no desempenho escolar, profissional ou na comunicação social. Quando o indivíduo se comunica permite ao outro que conheça seus pensamentos, sentimentos, necessidades e passa a conhecer os sentimentos, pensamentos e necessidades do outro. Podemos nos comunicar com o outro escrevendo, dizendo, representando ou mesmo gesticulando. Todas estas formas de comunicação podem ser agrupadas, por alguns estudiosos, na nomenclatura de comportamento verbal e constituem uma aquisição recente da espécie humana.

No caso da Comunicação Mediada por Computador Herring (1996) define a como a comunicação que se dá entre seres humanos através da instrumentalização de computadores. A CMC pode ocorrer em diversas modalidades - textual, gráfica, auditiva, visual, entre outras, a que interessa para nosso objeto de pesquisa é a CMC baseada em textos. Os participantes interagem através da palavra escrita, digitando mensagens que são simultaneamente lidas por outras pessoas em suas respectivas telas de vídeo - CMC síncrona (chat) - ou em algum outro momento posterior - CMC assíncrona(fórum, e-mail e blog's).A comunicação mediada por computador (CMC) tem proporcionado o surgimento de novas formas de sociabilidade, onde indivíduos se aglutinam em torno de interesses comuns, independente das distâncias espaciais.

Apesar do amplo uso do computador na educação especial, ainda são poucas as pesquisas que fazem referência a sua aplicação às pessoas com autismo, principalmente no que se refere ao seu uso como ferramenta para mediação de comunicação. Isto foi, sem dúvida, um dos motivos que levaram a pesquisar mais sobre o assunto e que acabou gerando este projeto de pesquisa.

\section{Marcadores Conversacionais}

De acordo com Marcuschi (2002), existem relações estruturais e lingüísticas entre a organização da conversação em turnos e a ligação interna em unidades constitutivas de turno. Os marcadores do texto possuem funções tanto conversacionais quanto sintáticas e podem ser divididos em três categorias: verbais, não-verbais e supra-segmentais. Os marcadores podem funcionar como iniciadores de turno ou unidade comunicativa, ou como finalizadores. Marcadores são palavras ou expressões bastante estereotipadas. Eles aparecem no contexto geral, particular ou pessoal da conversação, e não dependem especialmente de novas informações para o desenvolvimento do tópico.

Os marcadores conversacionais são de relevante importância, pois ajudam a construir e dar coerência e coesão, funcionando como articuladores e determinando as expressões de interação entre os interlocutores.

Quanto a sua forma, os marcadores podem ser verbais ou não-verbais. Os verbais encontrados podem ser lexicados, ou seja compostos por palavras como "sabe?" "eu 
acho que" ou então não lexicados com expressões do tipo "ahn", "eh" etc. Os nãoverbais podem ser as pausas mais alongadas e as ênfases em frases ou sílabas para demarcação.

Na questão semântica, a maioria desses marcadores não apresenta nenhuma importância para o entendimento do texto, mas às vezes expressões como "eu acho que", "eu tenho a impressão" não contribuem efetivamente para o desenvolvimento do tópico conversacional (assunto), mas tem como função revelar um ponto de vista do falante ou testar o grau de atenção do ouvinte.

Quanto às funções desses marcadores, eles podem desempenhar funções mais genéricas, como de articuladores e estruturadores e funções mais específicas de monitoramento do ouvinte, da busca de aprovação, sinalizadores de hesitação, de atenuação ou de reformulação além da intenção e interação do falante.

\section{Autismo e déficits de comunicação}

O transtorno autista está compreendido entre os transtornos invasivos do desenvolvimento que causam prejuízos severos nas diversas áreas do desenvolvimento, dentre elas, a da interação social.

Os critérios mais aceitos para definir ou diagnosticar pessoas com autismo são os da Organização Mundial da Saúde, registrados no DSM IV ${ }^{1}$, que define o seguinte:

- Comprometimento qualitativo da interação social;

- Comprometimento qualitativo da comunicação, manifestado por, pelo menos, um dos seguintes aspectos:

(a) atraso ou ausência total de desenvolvimento da linguagem falada (não acompanhado por uma tentativa de compensar por meio de modos alternativos de comunicação, tais como gestos ou mímica);

(b) em indivíduos com fala adequada, acentuado comprometimento da capacidade de iniciar ou manter uma conversa;

(c) uso estereotipado e repetitivo da linguagem ou linguagem idiossincrática;

(d) ausência de jogos ou brincadeiras de imitação social variados e espontâneos próprios do nível de desenvolvimento

- Padrões restritos e repetitivos de comportamento, interesses e atividades,

Quase sem exceção, as pessoas com autismo apresentam atraso ou ausência total no desenvolvimento da linguagem verbal, que não é compensado pelo uso da gestualidade ou outras formas de comunicação. Apesar de não demonstrarem alterações significativas no balbucio, praticamente, a metade dessas crianças não adquire linguagem verbal e, as que adquirem, apresentam sérios desvios de linguagem.

\footnotetext{
${ }^{1}$ Diagnostical Statistical Manual, desenvolvido pela Associação Americana de Psiquiatria (APA, 1994).
} 
As pessoas com autismo que desenvolveram linguagem apresentam dificuldades marcantes em iniciar ou sustentar diálogos e, muitas vezes, apesar de se utilizarem da fala, não visam comunicação.

Nas crianças que falam, o uso restrito e estereotipado da linguagem é bem descrito. Por exemplo, Kanner (1943) descreveu uma menina autista que seguia uma rígida rotina antes de ir dormir, exigindo que sua mãe participasse de um diálogo que era idêntico dia após dia. Outros aspectos da linguagem restrita e estereotipada são a ecolalia imediata ou tardia, a inversão pronominal, a linguagem metafórica e a invariabilidade do ritmo e tonalidade da linguagem verbal.

Abaixo podemos verificar um diálogo com um sujeito autista, que demonstra alguns déficits relacionados ao uso dos marcadores verbais:

\section{R: Bom dia \\ R: Ficou acordado direto? \\ D: não sai da cama as 10 pra as 8 da manhã \\ R: ah tá \\ R: E foi dormir que horas? Era 1:00 ainda estava online \\ D: vi as series h20 meninas e clube do travesseiro \\ D: h20 meninas sereias \\ R: Em qual canal da tv? \\ D: o que fez sabado passado \\ D: 57 \\ D: durante a semana farroupilha \\ R: Como tenho um bebê pequeno, fica complicado sair de casa assim \\ D: os gaucho dai gostam de churrasco \\ D: da região de passo fundo \\ (Diálogo com o sujeito D, realizado no dia 23/09/2008)}

O Sujeito D é uma pessoa com asperger, alfabetizado, 33 anos que mantém diálogo freqüente utilizando o MSN(The MicroSoft Network) .Pode-se perceber, por exemplo, a ausência de resposta na saudação feita por R. Na seqüência, percebe-se ainda a falta de utilização de pontuação e falta de seqüência no diálogo.

Sujeitos com Asperger tipicamente têm um modo de falar altamente artificial, usando um registro formal, muitas vezes, impróprio para o contexto. Uma criança de cinco anos de idade com essa condição pode falar regularmente como se fizesse um discurso quando o assunto lhe interessa (ATTWOOD, 1997).

A interpretação literal é característica muito comum, embora não universal, da Síndrome de Asperger. Attwood (1997) dá o exemplo de uma menina com Asperger que um dia atendeu ao telefone e o falante perguntou para ela: "Paul está aí?". Paul estava em casa, mas não no mesmo quarto que ela. Assim, após olhar em volta para se certificar disso, a menina simplesmente respondeu "Não" e desligou. A pessoa do outro lado da linha teve de ligar novamente e explicar a ela que queria que a menina encontrasse o Paul e passasse o telefone a ele.

Sujeitos com Asperger também possuem uma dificuldade em entender as metáforas, ou seja, também, nestes casos, interpretando de modo literal, como, por exemplo, a expressão, "nem que chova canivetes". Apesar destas dificuldades, eles podem 
demonstrar aptidão avançadas demais em relação à fala, leitura, matemática, noções de espaço ou música, às vezes, no nível de "superdotados", mas estes talentos são contrabalançados por retardamentos consideráveis no desenvolvimento de outras funções cognitivas. Assim como já visto neste capítulo, no que se refere às características das pessoas com autismo, o Aspeger possui outras características comuns como ecolalia (repetição ou eco da fala do interlocutor) e palilalia (repetição de suas próprias palavras).

\section{Análise de marcadores em ambientes síncronos: dialog}

O primeiro passo para se fazer a análise dos marcadores é o armazenamento de diálogos. Para que isso seja possível, foi obtida a autorização dos pais dos sujeitos que farão parte da pesquisa, observando os preceitos éticos que estão envolvidos no processo e garantindo o anonimato dos participantes. Atualmente, já estão sendo coletados diálogos com o sujeito A, uma pessoa autista, de 33 anos, do sexo masculino e alfabetizado, mesmo sem ter freqüentado e escola normal. Este processo está ocorrendo desde o dia 16 de agosto de 2008 e, atualmente, já foram armazenados 16 diálogos, sendo aproximadamente dois por semana. O sujeito B selecionado é um autista de 17 anos, freqüenta escola especial, também do sexo masculino e alfabetizado. Os diálogos com o segundo sujeito B ainda não foram realizados, pois estão sendo aguardadas a autorização e assinatura do Termo de Consentimento descrito anteriormente, para o inicio do processo de coleta. As interações estão sendo realizadas através do comunicador síncrono MSN Messenger e armazenadas no formato XML, padrão do próprio aplicativo e organizados por data e hora da interação, com a finalidade de facilitar a classificação. Estes diálogos são armazenados para que, posteriormente, sejam classificados os déficits de comunicação através do software Dia-Log e inserida a análise do pesquisador quanto aos marcadores utilizados no diálogo. O Dia-Log é um software desenvolvido especialmente para esta pesquisa, totalmente em ambiente web e que permite classificar os diálogos coletados através do MSN, conforme mostra a Figura 1.

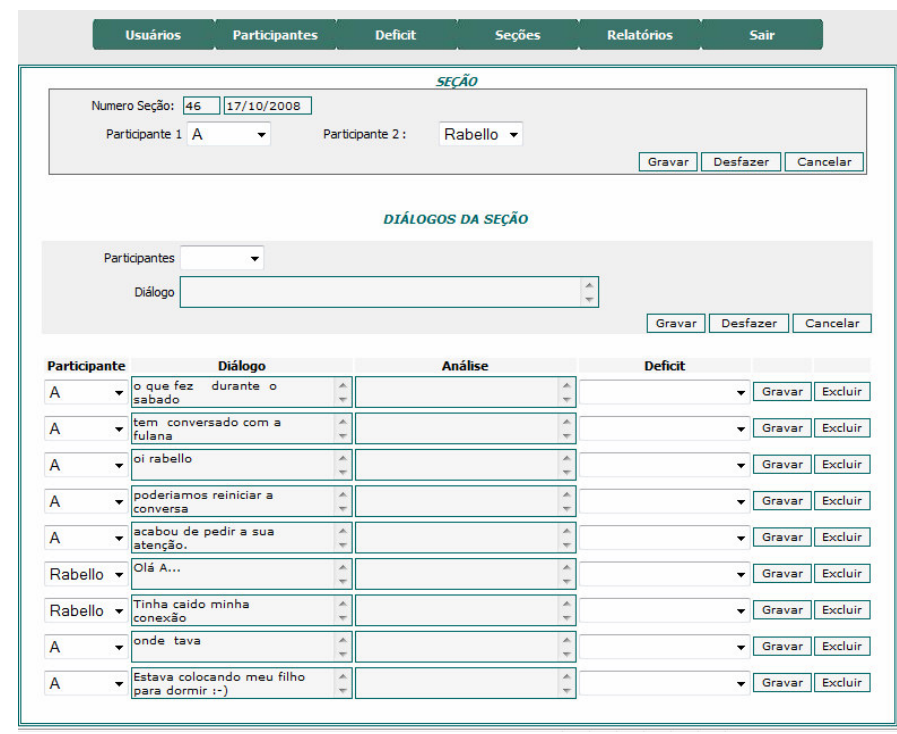

Figura 1 - Formulário para registro dos diálogos no software Dia-Log. 


\section{Fonte: Primária.}

Na Figura 1, podemos verificar ainda como o diálogo foi armazenado, ou seja, além das informações referente aos participantes, o pesquisador pode editar as informações referentes a sua análise e classificação dos déficits encontrados no diálogo.

O período de coleta e de iteração através de MSN será de 4 meses, ou até completar 50 diálogos com cada sujeito. Há a possibilidade da fase ser interrompida antes, assim que se detectar que os marcadores estão repetindo freqüentemente e não se apresenta novos dados para análise e classificação.

O software de registro dos diálogos permite que outros pesquisadores também possam avaliar e registrar os déficits de conversação, pois o mesmo está disponível para um acesso via web com segurança garantida por um login com usuário e senha.

Nesta fase de coleta, é importante ressaltar que a detecção e classificação dos deficits de comunicação, a partir dos marcadores conversacionais, organização dos turnos e pares adjacentes, serão realizadas com a utilização do software Dia-Log. Na seqüência, após essa classificação, começa a fase de desenvolvimento do mediador, utilizando agentes para identificar em tempo real os déficits de comunicação.

Nesta fase serão apenas coletados os diálogos e armazenados para que os especialistas possam fazer a classificação dos déficits de comunicação. Esta classificação será realizada posteriormente pelos próprios agentes inteligentes, após treinados com a base criada durante a coleta com a utilização do MSN Messenger e armazenados no DIALOG.

Para o desenvolvimento do sistema de bate-papo, serão utilizados agentes inteligentes, os quais funcionam como assistentes pessoais que auxiliam o usuário em suas mais diversificadas tarefas, nesse caso, eles auxiliarão os usuários a interagirem com a ferramenta em si e com os outros usuários da sessão, fazendo com que o aprendizado se torne atraente e desafiador.

Além do agente fazer a mediação do ambiente no momento correto, é importante que ele não tire a concentração do usuário no tema debatido, apenas dê algumas dicas e/ou sugestões, fazendo com que o usuário continue com a atenção voltada para o diálogo.

Para desenvolvimento do chat, será utilizado o Jchatbox ${ }^{2}$, um software de categoria livre, desenvolvido em Java e com código aberto. Optou-se por utilizar um software livre, pois o objetivo deste trabalho não é o desenvolvimento do bate-papo, mas a integração deste com os agentes que farão a mediação da conversação. Esta aplicação poderá ser, posteriormente, acessada a partir de qualquer outra ferramenta de EAD de código aberto como Teleduc ou Moodle.

Para integrar o agente ao chat jchatbox, será utilizado o framework $\mathrm{JADE}^{3}$ (Java Agent Development Framework), que é um ambiente para desenvolvimento de aplicações baseadas em agentes, conforme as especificações da FIPA ${ }^{4}$ (Foundation for Intelligent

\footnotetext{
2 Pode ser feito o download no endereço http://www.javazoom.net/jzservlets/jchatbox.

3 Jade é uma marca registrada do TILAB (http://www.telecomitalialab.com), anteriormente conhecida como CSELT. Foi desenvolvida pelo TILAB juntamente com o AOT (http://aot.ce.unipr.it) com a permissão do TILAB.

${ }^{4}$ Veja em http://www.fipa.org.
} 
Physical Agents), para interoperabilidade entre sistemas multiagentes totalmente implementado em Java. Foi desenvolvido e suportado pelo CSELT da Universidade de Parma na Itália. É open source (LGPL7). Segundo JADE (2008), o principal objetivo do framework é simplificar e facilitar o desenvolvimento de sistemas multiagentes, garantindo um padrão de interoperabilidade através de um abrangente conjunto de agentes de serviços de sistema. Optou-se pelo JADE por ser um framework desenvolvido em Java, facilitando a integração com o jchatbox.

Após a conclusão da integração do chat com os agentes de mediação, pode-se partir para a fase de validação, em que se verificará se a utilização desta tecnologia poderá contribuir para a detecção dos marcadores conversacionais para, posterior, compensação dos déficits detectados.

Os dados coletados, armazenados e classificados no DIA-LOG, serão analisados através de uma comparação entre comportamentos observados nos diálogos sem a utilização de agentes e com o uso de agentes inteligentes como mediadores do processo.

É nesta fase que ocorrerá a validação do sistema desenvolvido, ou seja, a partir da comparação dos dados que foram armazenados no Dia-Log com a classificação obtida pelo sistema de comunicação síncrona com a mediação de agentes.

Complementarmente a pesquisa de cunho qualitativo será desenvolvida uma pesquisa de caráter tecnológico, na qual se desenvolverão ferramentas e soluções tecnológicas para as diferentes etapas da pesquisa qualitativa. Num primeiro momento, na fase de coleta, serão armazenados e classificados os diálogos realizados no MSN Messenger, através da ferramenta desenvolvida especificamente para esta pesquisa, chamada Dia-Log. Este software foi desenvolvido especificamente para esta fase, visto que um dos objetivos é integrar diretamente o banco de dados do Dia-Log com um chat de categoria livre, pois não se deterá no desenvolvimento da ferramenta de comunicação síncrona. A este chat será incorporado o agente inteligente que terá a função de realizar a análise da conversação, identificar os marcadores e propor mecanismos de compensação em tempo real, na forma de sugestão ao usuário. Antes disso, será definida, inicialmente, uma ontologia ${ }^{5}$, em que serão descritos os conjuntos de conceitos sobre o domínio e ferramenta desenvolvida para a pesquisa. Este processo, desde coleta até a validação do software, pode ser visualizado na figura 2.

5 Na Ciência da Computação, ontologia é um modelo de dados que representa um conjunto de conceitos dentro de um domínio e os relacionamentos entre estes. 


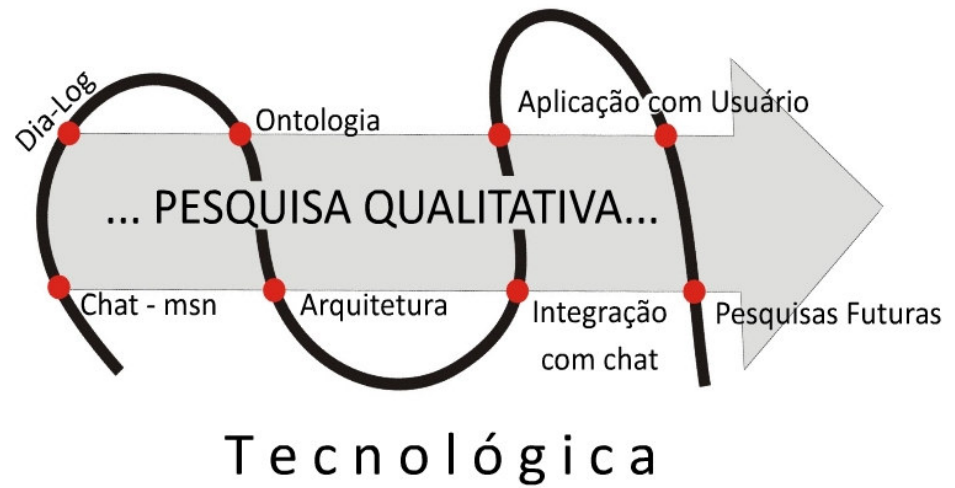

Figura 2 - Ilustração do fluxo do projeto Fonte: Primária.

\section{Considerações Finais}

Percebe-se a partir do referencial teórico descrito neste artigo que comunicação é central para a interação social e esta pode interferir significativamente no desempenho escolar, profissional ou na comunicação social. No caso das pessoas com autismo, os sujeitos que desenvolveram linguagem apresentam dificuldades em iniciar ou sustentar diálogos e, muitas vezes, apesar de se utilizarem da fala, não visam comunicação. Sendo assim, pretende-se com este trabalho, identificar através da análise dos marcadores conversacionais utilizando o software dia-log, os déficits de comunicação de pessoas com autismo. Esta identificação vai ser utilizada para criar uma base de conhecimento que proporcionará aos agentes inteligentes uma intervenção através de um chat, que proponha ao usuário formas de compensação. Este método auxiliará a pessoa autista a manter a interação e conseqüentemente desenvolver as habilidades sociais, melhorando sua qualidade de vida e principalmente, sua inserção na sociedade.

\section{Referências}

AMERICAN PSYCHIATRY ASSOCIATION. DSM-IV, diagnostic and statistical manual for mental disorders. 4th edn. Washington, DC: APA, 1994.

ATTWOOD, Tony. Asperger's syndrome: a guide for parents and professionals. London: Jessica Kingsley, 1997.

FACION, José Raimundo. Transtornos invasivos do desenvolvimento associados a graves problemas do comportamento: reflexões sobre um modelo integrativo. Brasília, DF: Ministério da Justiça, CORDE, 2002.

HERRING, S. Posting in a different voice: gender and ethics in CMC. Ess, C. (ed.). Philosophical Perspectives on Computer-Mediated Communication, Alabany, State University of New York Press, 1996.

HOBSON, P. The autistic child's appraisal of expressions of emotion: a further study. Journal of Child Psychology and Psychiatry, n. 27, p. 671-680, 1986.

JADE. Disponível em: <http://jade.tilab.com>. Acesso em: 15 out. 2008. 
KANNER, L. Affective disturbances of affective contact. Nervous Child, n. 2, p. 217250, 1943.

LYRA, Luciana de Castro. O uso de marcadores discursivos na fala de indivíduos com síndrome de Asperger. 2007. Dissertação (Mestrado em Lingüística) - Universidade Federal do Rio de Janeiro. Rio de Janeiro, 2007.

MARCUSCHI, Luis Antônio.Gêneros textuais e ensino.Rio de Janeiro: Lucerna, 2002. ORECCHINI, Catherine Kerbrat. Análise da conversação: princípios e métodos. Parábola Editorial, 1996.

PASSERINO, Liliana Maria. Interação social e mediação de processos cognitivos de pessoas com autismo em ambientes digitais de aprendizagem: uma abordagem sóciohistórica. 2005. 320 f. Tese (Doutorado em Informática na Educação) - Universidade Federal do Rio Grande do Sul. Porto Alegre, 2005.

TOMASELLO, M. Orígenes culturais da aquisição do conhecimento humano. São Paulo: Marins Fontes, 2003.

VICCARI, R. M.; GIRAFFA, L. Sistemas tutores inteligentes: abordagem tradicional x abordagem de agendas. SBIA, XIII. Curitiba, 1986.

WATZLAWICK, Paul; BEAVIN, Janet Helmick; JACKSON, Don D. Pragmática da comunicação humana. São Paulo: Cultrix, 2000. 